\title{
Clinical investigation of reproductive cases in cows and buffaloes at teaching veterinary hospitals in India
}

\begin{abstract}
Reproductive disease is a generic term that refers to all diseases which affect the organs of reproductive system in animals. It occurs in cattle buffalo, sheep, goat, horse etc. and causes heavy economic loss by reducing the reproductive activity of the animal along with calf mortality. The study was undertaken to know the proportionate prevalence of reproductive cases in cattle and buffalo in Veterinary College and Research Institute (VCRI), Namakkal and Madras Veterinary College (MVC), Tamilnadu, India .The duration of the study was 1.5 months and total 286 of different cases were registered during the study period. Both retrospective and prospective reproductive cases were included in this study. The proportionate prevalence of different reproductive cases were respectively $5.2 \%$ and $8.8 \%$ dystocia; $4.6 \%$ and $5.3 \%$ respectively retained placenta; $3.5 \%$ and $7.9 \%$ abortion respectively; $2.9 \%$ and $2.7 \%$ ovarian cyst respectively in VCRI and MVC. Reproductive cases were more frequently occurred in cross-breeds. Older animals $(42.1-87.5) \%$ with higher parity $(31-87.5) \%$ was susceptible to reproductive cases. Antibiotics and hormonal drugs were used for the treatment of reproductive cases. Most of the reproductive cases/ dystocia were corrected manually where the complicated cases were performed by caesarean operation.
\end{abstract}

Keywords: reproductive disease, parity, services, management
Volume 4 Issue I - 2016

\author{
Mahe Alam,' KM Fakhrul Islam,' Mohammad \\ Rafiul Hoque,' Nasir Uddin, ${ }^{2}$ MdNurul \\ Quader,' Md. Iqbal Hossain,' Hatem Sazzad \\ Md. Zulkar Nine ${ }^{3}$ \\ 'Chittagong Veterinary and Animal Sciences University, \\ Bangladesh \\ 2USAID's Bagh Activity, Bangladesh \\ ${ }^{3}$ Banghobonshu Sheikh Mujib Safari Park, Bangladesh
}

Correspondence: KM Fakhrul Islam, Faculty of Veterinary Medicine, Chittagong Veterinary and Animal Sciences University, Khulshi, Chiattagong-4225, Bangladesh,

Email fakhruldvmI5@gmail.com

Received:September 10, 2016 | Published: October 06, 2016

\section{Introduction}

Reproductive diseases and disorders are frequently occurred in livestock in subcontinent and cause significant economic losses. ${ }^{1}$ Common reproductive cases are dystocia, retained placenta, abortion, ovarian cyst etc. Dystocia comes from a Greek word "Dys" meaning "difficult," and "Tokos" meaning "childbirth. When the first or especially the second stage of parturition is markedly prolonged or becomes difficult for the dam to deliver without intervention, the condition is termed as dystocia. ${ }^{2}$ Retained placenta is a complication of dystocia which is defined as failure to expel fetal membranes within 24 hours after parturition. ${ }^{3}$ Abortion in dairy cattle is commonly occurred as a loss of the fetus between the age of 42 days and 260 days. ${ }^{4}$ Common causes of abortion includes infectious diseases such as brucellosis, genetic abnormalities, heat stress, toxic agents and ergot alkaloids. ${ }^{4}$ Cyst associated with ovary and surrounding structures are common which may be congenital or acquired and causes infertility of animal. ${ }^{5}$

Causes associated with the occurrence of dystocia are uterine inertia, ruptured uterus, insufficient pain, ruptured diaphragm, perforated trachea and insufficient dilatation of birth canal., Risk factors involved with dystocia includes age of first calving, debility, crossbreed, concentrate diet, diseases such as Leptospirosis, Brucellosis, Schistosomosis, mummification of fetus, artificial insemination, prolonged gestation period etc. ${ }^{8,9}$ The consequences of dystocia develop vaginal prolapsed, uterine inertia, vaginal rupture, pyometra, retained placenta and endometritis. ${ }^{6,7,10}$

The present study was conducted at Teaching Veterinary Hospitals (Veterinary College and Research Institute, Namakkal and Madras Veterinary College, Chennai). These two Veterinary Hospitals are well recognized hospitals for animal health care in India. Both pet and large animals are properly treated. The Madras Veterinary College Hospital has more than 100years' experience of animal health service history. These two veterinary hospitals play vital role to the economy of India.

Around 286 clinical cases of multiple species were handled during 1.5 months internship period at Veterinary Hospitals of VCRI and MVC in India. However this clinical report focused on reproductive cases in large ruminants with the following set objectives:

a. To estimate the proportionate prevalence of reproductive clinical cases in cattle and buffaloes

b. To know the clinical features of dystocia and its complications in cows and buffaloes

c. To describe the management of dystocia in cows and buffaloes

\section{Materials and methods}

One and half month clinical study (May-July2015) was carried out on reproductive and other clinical cases in cattle and buffaloes at Teaching Veterinary Hospital of VCRI, Namakkal and of MVC, Chennai, India. Each case was undergone clinical and physical examination. In some cases clinical diagnosis was performed by specialized diagnostic techniques such as ultrasonography for ovarian cyst, hormone assay for pregnancy diagnosis and heat detection etc. Species, breed, age, no. of parity, body condition score and services were recorded for each case using internship log book. Close inspection and farmer's interview were done for recording information and clinical diagnosis of cases.

Age was determined according to dentition, observing horn ring, and by interviewing to farmers. Breed was defined according to phenotypic characteristics of animal. Body condition score was 
assessed as per description of Nicholson. ${ }^{11}$ Abortion is defined as when a pregnancy ends abruptly, either voluntarily or involuntarily, and the fetus is expelled from the womb before it can live on its own. ${ }^{4}$ Retained placenta is confirmed by failure to expel fetal membranes within 24hours after parturition. ${ }^{3}$ Ovarian cyst was diagnosed by rectal palpation. ${ }^{5}$ On Ultrasonography ovarian cysts are follicular structures having a diameter of at least 2.5 centimeters (about 1 inch) that persist for 10 or more days on the ovaries in the absence of a functional corpus luteum.

Before handling the reproductive cases particularly dystocia position of the fetus in the birth canal of the animal was determined. Rope, hook, snare, distortion pit etc. were used for manual removal of fetus. Cases were corrected as per approved methods..$^{12,13}$

Types of treatment, Intervention and types of drugs used for each case were also recorded. Data obtained were entered into Microsoft
Excel 2007 and exported to STATA (Stata Crop, 4905, Lakeway River, College Station, Texas 77845, USA) for analysis. Descriptive statistics were performed. Proportionate prevalence of each reproductive case was calculated by a total number of particular reproductive events divided by the total number of clinical cases. Results were expressed as frequency number and percentage against each category of variable.

\section{Results}

\section{Proportionate prevalence of reproductive and other clinical cases}

Regardless of species, the proportionate prevalence of different reproductive cases was respectively $5.2 \%$ and $8.8 \%$ dystocia in VCRI and MVC; $4.6 \%$ and $5.3 \%$ respectively retained placenta in VCRI and MVC; $3.5 \%$ and $7.9 \%$ abortion respectively in VCRI and MVC;2.9\% and $2.7 \%$ cyst respectively in VCRI and MVC (Table 1 ).

Table I Proportionate prevalence of reproductive and other clinical cases in VCRI and MVC, India

\begin{tabular}{lllll}
\hline \multirow{2}{*}{ Diseases or disorders } & \multicolumn{2}{l}{ VCRI, Namakkal } & \multicolumn{2}{l}{ MVC, Chennai } \\
\cline { 2 - 5 } & N & $\%$ & N & $\%$ \\
\hline Dystocia & 9 & 5.2 & 10 & 8.8 \\
Retained placenta & 8 & 4.6 & 6 & 5.3 \\
Abortion & 6 & 3.5 & 9 & 7.9 \\
Ovarian cyst & 5 & 2.9 & 3 & 2.7 \\
Foot and Mouth Disease & 14 & 8.1 & 12 & 10.5 \\
Mastitis & 8 & 4.7 & 11 & 9.6 \\
Black Quarter & 3 & 1.7 & 1 & 0.9 \\
Tetanus & 6 & 3.5 & 2 & 1.8 \\
Pneumonia & 5 & 2.9 & 2 & 1.8 \\
Fungal infection & 6 & 3.5 & 5 & 4.4 \\
Babesiosis & 4 & 2.3 & 2 & 1.8 \\
Endoparasitic infestation & 45 & 26.2 & 12 & 10.5 \\
Ectoparisitic infestation & 18 & 10.2 & 9 & 7.9 \\
Cornial opacity & 1 & 0.6 & 2 & 1.8 \\
Conjunctivitis & 0 & 0 & 1 & 0.9 \\
Acidosis & 14 & 8.3 & 13 & 11.4 \\
General weakness & 20 & 11.6 & 14 & 12.3 \\
Total & 172 & & 114 & \\
\hline
\end{tabular}

VCRI, veterinary college and research institute; MVC, madras veterinary college

\section{Distribution of reproductive cases by species and breed}

Reproductive cases were more frequently occurred in crossbreed than in local breed in both species (Table 2). The proportionate prevalence of reproductive cases was $12.5-57.9 \%$ in young and $42.1-87.5 \%$ in older animals; $12.5-68.4 \%$ during the first parity and $31.6-87.5 \%$ during the second and subsequent parities; $22.2-75 \%$ in normal body condition score and $25-77.8 \%$ in poor body condition score; $22.2-37.5 \%$ in natural services and $62.5-77.8 \%$ in artificial insemination (Table 3).

\section{Treatment and Management of different reproductive cases}

Manual intervention with hormonal drugs was applied for 13 dystocial cases whereas surgical intervention was performed for 6 dystocial cases. After intervention 5\% normal saline, Oxytetracycline (a) $10 \mathrm{mg} / \mathrm{kg}$ body weight and vitamin AD3E were given for all cases. 
Retained placenta was removed manually for all cases with oxytocin@ $20 \mathrm{mg} / \mathrm{kg}$ body weight used for same cases. After removal antibiotic -oxytetracycline@10mg/kg body weight and vitamin were given. Aborted cases were treated with antibiotics- oxytetracycline @ 10mg/

Table 2 Frequency distribution of reproductive cases in cows and buffaloes at Teaching Veterinary Hospital in India

\begin{tabular}{|c|c|c|c|c|c|c|c|c|c|c|}
\hline \multirow{3}{*}{ Cases } & \multicolumn{4}{|c|}{ VCRI, Namakkal } & \multirow{3}{*}{$\mathbf{N}$} & \multicolumn{4}{|c|}{ MVC, Chennai } & \multirow{3}{*}{$\mathbf{N}$} \\
\hline & \multicolumn{2}{|l|}{ Cows } & \multicolumn{2}{|c|}{ Buffaloes } & & \multicolumn{2}{|l|}{ Cows } & \multicolumn{2}{|c|}{ Buffaloes } & \\
\hline & Local & Cross & Local & Cross & & Local & Cross & Local & Cross & \\
\hline Dystocia & 2 & 4 & 2 & 1 & 9 & 3 & 6 & 1 & 0 & 10 \\
\hline Retained placenta & 3 & 4 & 1 & 0 & 8 & 1 & 4 & 1 & 0 & 6 \\
\hline Abortion & 2 & 4 & 0 & 0 & 6 & 0 & 3 & 0 & 0 & 3 \\
\hline Ovarian cyst & 1 & 4 & 0 & 0 & 5 & 1 & 2 & 0 & 0 & 3 \\
\hline Total & 8 & 16 & 3 & 1 & 28 & 5 & 15 & 2 & 0 & 22 \\
\hline
\end{tabular}

Table 3 Distribution of reproductive cases by types and different factors

\begin{tabular}{|c|c|c|c|c|c|c|c|c|c|}
\hline \multirow{2}{*}{ Factor } & \multirow{2}{*}{ Category } & \multicolumn{2}{|c|}{ Dystocia } & \multicolumn{2}{|c|}{ Retained placenta } & \multicolumn{2}{|c|}{ Abortion } & \multicolumn{2}{|c|}{ Ovarian cyst } \\
\hline & & $\mathbf{N}$ & $\%$ & $\mathbf{N}$ & $\%$ & $\mathbf{N}$ & $\%$ & $\mathbf{N}$ & $\%$ \\
\hline & $\leq 3$ & 11 & 57.9 & 7 & 50 & 4 & 44.4 & I & 12.5 \\
\hline \multicolumn{10}{|c|}{ Age(year) } \\
\hline & $>3$ & 8 & 42.1 & 7 & 50 & 5 & 55.6 & 7 & 87.5 \\
\hline & First & 13 & 68.4 & 6 & 42.9 & 5 & 55.6 & I & 12.5 \\
\hline \multicolumn{10}{|l|}{ Parity } \\
\hline & Second and subsequent & 6 & 31.6 & 8 & 57.1 & 4 & 44.4 & 7 & 87.5 \\
\hline & 3 & 14 & 73.4 & 5 & 34.7 & 2 & 22.2 & 6 & 75 \\
\hline \multicolumn{10}{|l|}{ BCS } \\
\hline & $\leq 3$ & 5 & 26.3 & 9 & 64.3 & 7 & 77.8 & 2 & 25 \\
\hline \multirow{3}{*}{ Service } & Natural & 5 & 26.3 & 4 & 28.6 & 2 & 22.2 & 3 & 37.5 \\
\hline & & & & & & & & & \\
\hline & Artificial Insemination & 14 & 73.7 & 10 & 71.4 & 7 & 77.8 & 5 & 62.5 \\
\hline
\end{tabular}

BCS, body condition score

Table 4 Treatment and management of reproductive cases at Teaching Veterinary Hospital in India

\begin{tabular}{|c|c|c|c|c|}
\hline Treatment & Dystocia & Retained placenta & Abortion & Ovarian cyst \\
\hline Mannual & 13 & 14 & 9 & 8 \\
\hline Surgery & 6 & 0 & 0 & 0 \\
\hline \multirow[t]{2}{*}{ Drugs Given } & $\begin{array}{l}\text { 5\% Normal saline i/vly, } \\
\text { oxytetracycline@ I0mg/ } \\
\text { kgbwti/mly, }\end{array}$ & $\begin{array}{l}\text { Oxytocin@20IU/Kg bwt, i/mly, i/ } \\
\text { vlyoxytetracycline@I0mg/kgbwti/mly, }\end{array}$ & $\begin{array}{l}\text { Oxytetracycline@10mg/kg } \\
\text { bwti/mly, }\end{array}$ & $\begin{array}{l}\text { GnRH@I500IU/ } \\
\text { kgbwti/mly or i/vly. }\end{array}$ \\
\hline & vitamin & vitamin & Vitamin & vitamin \\
\hline
\end{tabular}

Citation: Alam M, Islam KMF, Hoque MR, et al. Clinical investigation of reproductive cases in cows and buffaloes at teaching veterinary hospitals in India.J Dairy Vet Anim Res. 2016;4(I):227-23I. DOI: 10.15406/jdvar.2016.04.00105 


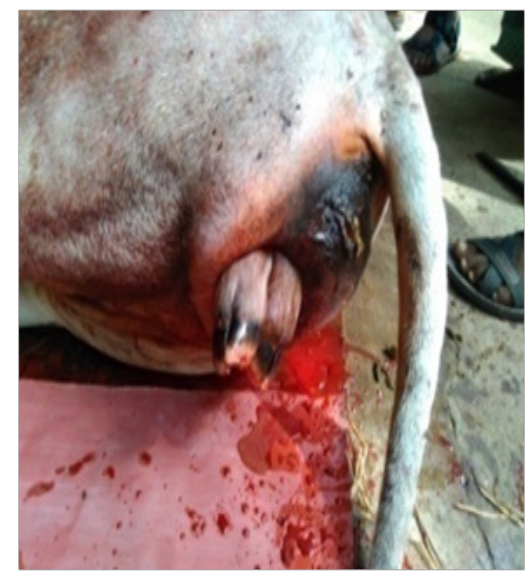

Figure Ia Protrusion of fetal fore limb.

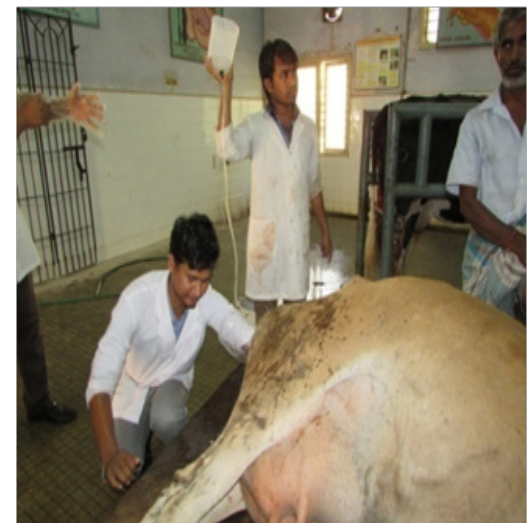

Figure Ic Examination of fetal position.

Figure I Different images of correction of dystocia in a cow.

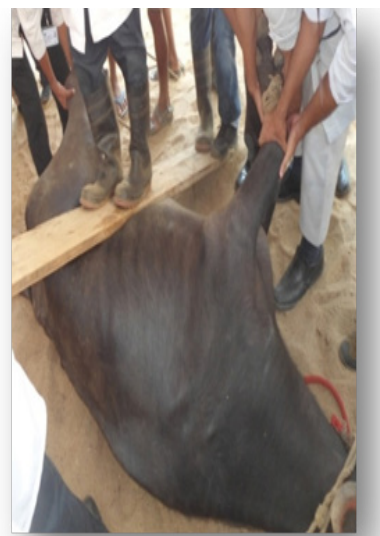

Figure 2a Animal on distortion pit.

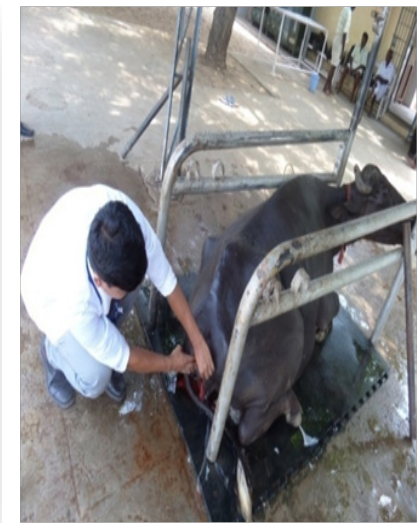

Figure $\mathbf{2 b}$ After correction of uterine torsion.

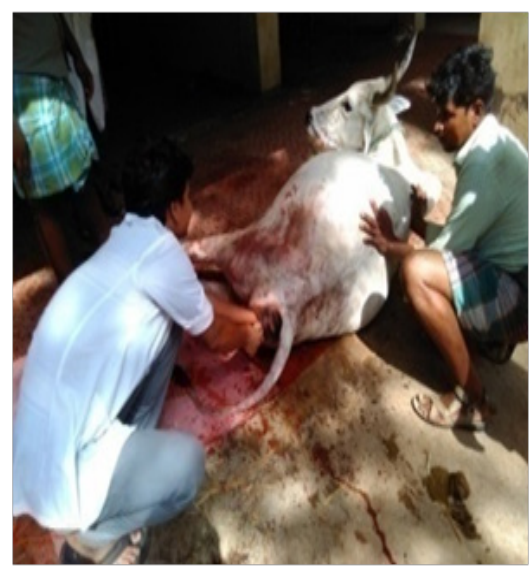

Figure Ib Pervaginal examination of animal.

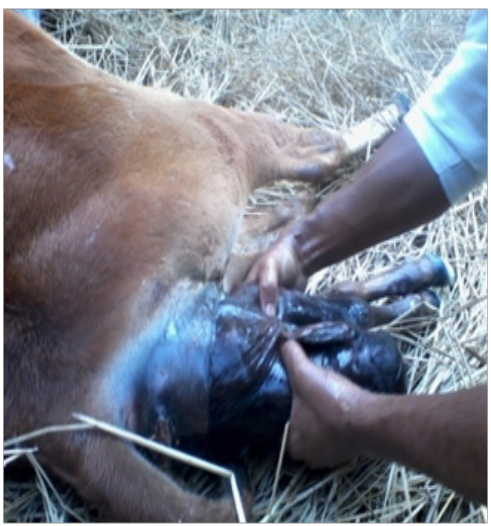

Figure Id Manually traction of fetus.

Figure 2 Different images of correction of dystocia in a buffalo.

\section{Discussion}

Reproductive cases are more frequently occurred in cows and buffaloes and causes heavy loses to the animals. The overall proportionate prevalence of dystocia; retained placenta; abortion and ovarian cyst in this study corresponds to earlier studies. ${ }^{3,5,14}$ Therewith, many previous studies reported that the incidence of dystocia is $6.9 \%$ in cattle ${ }^{3,14}$ and buffaloes $(0.70-6.3) \%$ in buffaloes ${ }^{15}$ which is coincide with our observation. This study showed that the occurrence of
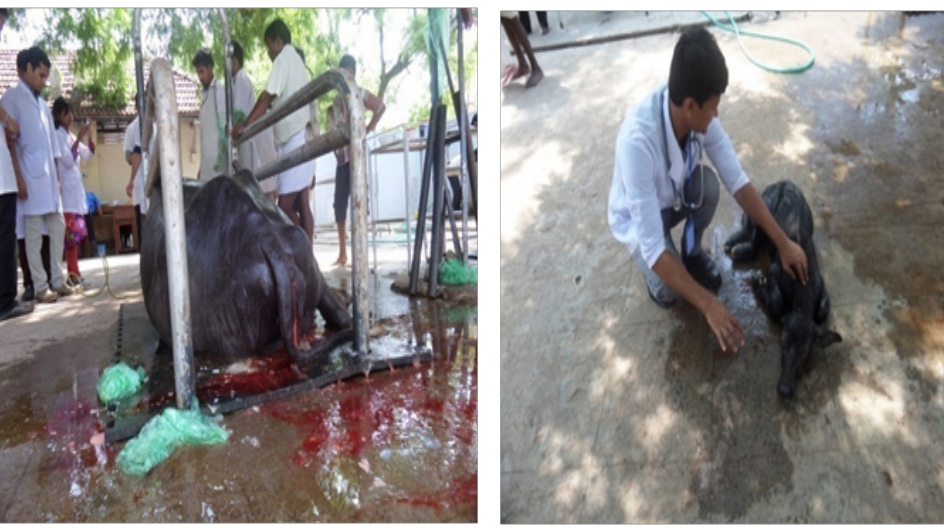

Figure 2c Animal after delivery. Figure 2d Care of new born calf reproductive cases commonly occurred in cross breeds (31.6-87.5)\% which is supported by Ahmed JU, ${ }^{16}$ Khair A et al., ${ }^{17}$ Esheti G. ${ }^{18}$ The proportionate prevalence of reproductive cases in older animals (42.1-87.5)\% with higher parity (31-87.5)\% was higher in this study, is agreed with many studies. ${ }^{19,20}$ Animals with artificial insemination were more susceptible to reproductive cases in the previous study which is coincided with the result of Eaglesom MD. ${ }^{21}$ Most of the reproductive cases were corrected manually where the complicated cases were corrected by caesarean operation. 
Either erythromycin or oxytetracycline along with other hormonal drugs were used for dystocia, retained placenta, abortion in this study which is supported other studies. ${ }^{5,22-24}$ Erythromycin or oxytetracline was used to prevent secondary bacterial infection. Intravenous infusion of 5\% normal saline to rehydrate the animal. Calcium therapy for contraction of muscle. Vitamin were given for proper growth and maturation of endometrial cells. Oxytocin was administered to increase uterine contraction so that the uterine debris come out quickly. Gonodotropin Releasing Hormone (GnRH) was applied for the treatment of ovarian cyst. These treatment rationale is supported by many studies. . $22,23,25-27^{2}$

\section{Limitations}

The number of clinical reproductive cases in this study was not big enough. Inclusion of retrospective reproductive cases was also a limitation as information of retrospective cases was not as accurate as prospective cases. The diagnosis of reproductive cases was based on clinical history, clinical signs.

\section{Conclusion}

Dystocia was higher in heifers than adult cattle and buffaloes Older animals with higher parity were commonly affected with the reproductive diseases. Cross breeds were more prone to reproductive cases. Artificial insemination and poor body condition score leads to reproductive disorders. Dystocia, abortion and ovarian cyst causes heavy damage to the reproductive system and reduces the reproductive activity. Most commonly used drugs for reproductive cases were antibiotics, NSAID, oxytocin, GnRH and vitamins. Most of the dystocia cases were corrected manually.

\section{Acknowledgements}

None.

\section{Conflict of interest}

Author declares that there is no conflict of interest.

\section{References}

1. Obese FY, Acheampong DA, Darfour-Oduro KA. Growth and reproductive traits of Friesian X Sanga crossbred cattle in the Accra plains of Ghana. African J Food Agr Nutri Develop. 2013;13(2):7957-7371.

2. Roberts SJ. Veterinary obstetrics and genital diseases. 2nd ed. UK: Edwards Brothers, WTSX; 2004. 227p.

3. Robert $\mathrm{O}$ Gilbert. Retained fetal membranes in large animal. The Merck Vet. Manual. 2014;34:312-322.

4. Hovingh E. Abortion in dairy cattle. USA: VCE Publication 404-288, Virginia Tech; 2009:1-4

5. Kesler DJ, Garverick HA. Ovarian cysts in dairy cattle: Review. $J A n i$ Sci. 1982;55(5):1147-1159.

6. Phogat JB, Bugalia NS, Gupta SL. Incidence and treatment of various forms of dystocia in buffaloes. Indian J Anim Reprod. 1992;13:69-70.

7. Biggs A, Osborne R. Uterine prolapsed and mid pregnancy uterine torsion in cows. Vet Rec. 2003;152(3):91-92.
8. SlossVA, Duftv JH. Handbook of Bovine Obstetrics. 4th ed. 1980;12:122-129.

9. Zaborski D, Grzesiak W, Szatkowska I, et al. Factors affecting dystocia in cattle. Reprod Domest Anim. 2009;44(3):540-551.

10. Rajala PJ, Gröhn YT. Effects of dystocia, retained placenta, and metritis on milk yield in dairy cows. J Dairy Sci. 1998;81(12):3172-3181.

11. Nicholson, Butterworth MH. A guide to condition scoring of zebu cattle J Ani Sci. 1986;29:1-15.

12. Agarwal SK, Tomer OS. Reproductive technologies in buffalo. Indian vet J. 1998;10:342-351.

13. Narayan G, Yogesh PB, Barolia, Kumar P. Maternal dystocia in cows and buffaloes. Vet Rec. 2011;1(2):41-53.

14. Gaafar HM, ShamiahShM, Hamd MA, et al. Dystocia in Friesian cows and its effects on postpartum reproductive performance and milk production. Trop Anim Health Prod. 2011;43(1):229-234.

15. Buffalopedia belongs to Central Institute for Research on Buffaloes. Indian Council of Agricultural Research. Dystocia. 2015.

16. Ahmed JU. An abattoir survey of female reproductive disorders in cattle of in Sweden. Bangladesh Vet J. 1984;18:55-58.

17. Khair A, Alam MM, Rahm AK, et al. Incidence of reproductive and production diseases of cross bred dairy cattle in Bangladesh. Bangladesh J. 2013;11(1):31-36.

18. Esheti G, Moges N. Major reproductive health disorders in cross breed dairy cows in Ethiopia. Glob Vet. 2014;13(4):444-449.

19. Gröhn YT, Erb HN, McCulloch CE, et al. Epidemiology of reproductive disorders in dairy cattle: associations among host characteristics, disease and production. Prev Vet Medi. 1990;8(1):25-39.

20. Kaikini AS, Chikalikar GK, Dindorkar CV. Reproductive disorders in Holstein-Friesian x Gir F1 crossbred cows. Indian J Ani Sci. $1983 ; 53: 556-558$

21. Eaglesom MD, Garcia MM. Disease risks to animal health from artificial insemination with bovine semen. Rev Sci Tech. 2008;16(1):215-225.

22. Bartolome JA, WW Thatcher, P Melendez, et al. Strategies for the diagnosis and treatment of ovarian cysts in dairy cattle. $J$ Am Vet Med Assoc. 2005;277(9):1409-1414.

23. Braw-Tal R, S Pen, Z Roth. Ovarian cysts in high-yielding dairy cows Theriogenology. 2009;72(5):690-698.

24. Casida LE, McShan WH, Meyer RK. Effect of unfractioned pituitary extract upon cystic ovaries and nymphomania in cows. J Ani Reprod. 1944;3:273-282.

25. Bierschwal CJ, Garverick HA, Martin CE, et al. Clinical response of dairy cows with ovarian cysts to GnRH. J Ani Sci. 1975;41(6):1660-1665.

26. Nanda AS, Ward WR, Dobson H. Lack of LH response to oestradiol treatment in cows with cystic ovarian disease and effect of progesterone treatment or manual rupture. Res Vet Sci. 1991;51(2):180-184.

27. Seguin BE, Convey EM, Oxender WD. Effect of gonodotropin releasing hormone and human chorionic gonadotropin on cows with ovarian follicular cysts. Am J Vet Res. 1976;37(2):383-387. 